proportionately with the amount of sunlight cut off, the earth and moon should produce effects inversely proportional to the square of their diameters, i.e. $13.5: \mathrm{I}$, and in analysing the collected data Dr. Bauer finds that the ratio of the diurnal variation to the eclipse variation is of this order, thereby supporting the theory set forth in the preface.

\section{THE SOLIDIFICATION OF FLUORINE AND THE COMBINATION OF SOLID FLUORINE WITH LIQUID HYDROGEN.1}

I $N$ preceding researches we have shown that fluorine is liquefied at $-187^{\circ} \mathrm{C}$., and that, at this low temperature, it acts neither upon crystallised silicon, amorphous carbon, boron nor mercury; that, in short, its chemical activity is diminished, but that it still combines with production of flame with hydrogen and solid turpentine.

These researches have been continued since one of us has been able to obtain hydrogen in the form of a stable liquid boiling at $-25^{\circ}{ }^{\circ}{ }_{5} \mathrm{C}$., or at $20^{\circ}{ }_{5}$ absolute. Since the first experiments published on this subject it has been found that fluorine which is perfectly free from hydrofluoric acid does not attack glass at the ordinary temperature; hence it is now possible to enclose a definite volume of fluorine in a thinwalled glass vessel, and to submit it to the powerful cooling action furnished by the ebullition of liquid hydrogen.

A sealed glass tube filled with fluorine and placed in liquid oxvgen, boiling quietly under the atmospheric pressure, showed no trace of condensation. The same tube was lowered slowly into a double-walled vessel containing liquid hydrogen, so as to obtain a progressive cooling. A yellow liquid first appeared, which, after plunging wholly into the liquid hydrogen, froze to a yellow solid. On leaving the tube for some time in the liquid hydrogen, so that the temperature of the fluorine was cooled down to $20^{\circ} .5$ absolute, the solid fluorine, originally yellow, became white, resembling in this respect chlorine, bromine and sulphur. Experiments with liquid nitrogen showed that the melting point of fluorine is below $-210^{\circ} \mathrm{C}$., and a comparison with the melting point of oxygen, $38^{\circ}$ absolute, showed that $40^{\circ}$ absolute, or $-223^{\circ} \mathrm{C}$., is the most probable value for the melting point of fluorine. The ratio of the melting point to the boiling point is a little smaller than the ratios given by chlorine and bromine.

Experiments were also directed to another point, the question of the affinity of bodies for each other at low temperatures, and in view of the fact that fluorine possesses more powerful affinities than any other elements, it was interesting to determine whether any action was possible between liquid hydrogen and solid fluorine, both maintained at a temperature of $-25^{\circ}{ }^{\circ}$. In order to realise this experiment, a thin glass tube was taken containing about 5o c.c. of gaseous fluorine, which had been completely freed from hydrofluoric acid, the gas completely solidified in one of the points of the tube, and this then immersed in a hundred cubic centimetres of liquid hydrogen. When the temperature of the whole was lowered to that of the liquid hydrogen, the point containing the fluorine was broken off without removing the tube, so as to allow of contact between the hydrogen and the fluorine. A violent explosion was the result, sufficient heat being set free to raise the material to incandescence and to set fire to the hydrogen. The explosion was sufficiently powerful to reduce the fluorine tube and the double-walled hydrogen vessel to powder.

Helium is now the only gas which has not been obtained in the solid state.

\section{THE ACCUMULATION OF METEOROLOGICAL OBSER VATIONS.}

PROF. HANN contributes to the Meteorologische Zeitschrift for January a translation into German of that portion of Prof. Schuster's address before the British Association at Belfast (NATURE, vol. 1xvi. pp. 614-618) which deals

1 A raper, by Profs H. Moiss in and J. Dewar, read before the Paris Academy of Sciences, March 16. NO. 1743 , voL. 67$]$ with meteorological observations, and adds some comments from which the following extracts are translated.

Prof. Schuster's point of view is that of the theoretical physicist, and it is consequently different from that of the meteorologist, who cannot leave the demands of practical life out of account.

The professor's remarks as to the desirability of short and systematic series of observations for the study of definite problems, that is to say, the introduction of a kind of experimental method into meteorology, will certainly meet with universal approval, but this has already been done in several cases (study of thunderstorms, effect of forests on climate, \&c.). Simultaneously with such special observations the regular "routine observations" need in no wise be neglected; they appear to us to be indispensable.

Complaints as to the superabundance of meteorological observations are not new; it may be a quarter of a century since we read in an English periodical: "The need in meteorological science now is not observations, but brains to work out the results." It cannot be denied that there is some justification for this point of view, but it must be borne in mind that by reducing the number of meteorological records the number of "brains " who would discuss already available observations would hardly be increased.

A small amount of consideration will further show that the question of a temporary suspension of meteorological observations cannot be regarded as a practical one. 'The central institutions could take no such step, for they are not intended solely, or even primarily, to serve the ends of pure science, but chiefly to meet the dernands of practical life, which would not brook the interruption of observations for a lustrum. The answer given by Sir George Airy before a Treasury Committee appointed to inquire into the expenditure of the grant in aid of meteorology is characteristic in this connection. Asked whether there were reasons for continuing the publication of the detailed daily reports from the seven (first-class) observatories, Airy replied : "It is desirable they should be preserved, I think; and there is one point which is worth considering, and that is that the public feeling in favour of meteorological publications is very strong. . . I I get a great number of letters and applications of all kinds from persons that 1 know nothing about. Few requests are made for astronomical information. A greater number are made for magnetic information, but that is to a great extent for practical purposes; but I think that by far the greater number are for meteorological information. . . Popular feeling is an element not to be put out of question in matters of this kind." This from the same Airy who later on expressed the wish "that an absolute stop should be made from time to time in order to give what I venture to call breathing time." But practical and scientific demands alike pass over such desires.

Had Prof. Schuster ever been at the head of a meteorological office, he would know how constantly public authorities, to say nothing of private individuals, demand authentic meteorological data; he would then be able to estimate what public opinion would say if the director answered: "I have discontinued meteorological observations for five years, to obtain time and opportunity for discussing existing records."

Even if official observations were suspended, private observations would be continued, and a state of affairs would again be brought about similar to that which obtained before the introduction of an organised system of observation. Unchecked observations would be made with untested and badly exposed instruments, and a real waste of time would result, nay more, in many cases positive harm might be done by the circulation of inaccurate data. A natural interest, which has undoubtedly done good service in the past, would also be checked.

As regards the publication of results, it is only by means of such publications that it is possible on the one hand to exercise satisfactory supervision over the observations, and on the other to give all who desire it the opportunity of making use of existing records. To bury the results where they would be accessible only to the staff of an office would be a waste that would indeed justify complaints.

Least of all can we understand how Prof. Schuster could mistake the value of continuous homogeneous records or 
the extent of the injury that would be inflicted on the objects of such observations by a temporary interruption of the same. A large number of the problems presented by the physics of our globe can only be attacked with any hope of success from this basis; it is essential to have a number of well supervised principal stations in each country supplying an uninterrupted homogeneous series of observations. These stations are also of service in the study of climatological history, and are destined to prove of great importance in the study of meteorology in the future.

Only in a limited sense can we agree with Prof. Schuster's dictum that before commencing to observe we should make sure that our observations will prove of service, and will give answer to a definite question. Not even in the case of observatories do such instructions hold good. When addressed to private observers we would characterise them as "blinkers" which limit the range of vision to definitely laid down lines. We quote one example: when Schwabe began his sun-spot record, it must have appeared to specialists as a mere hobby, devoid of all scientific object; had it been otherwise astronomers would undoubtedly have commenced such observations earlier. And what scientific value have these observations now attained to?

\section{LEAD IN PEATY WATER. ${ }^{1}$}

$T$ HE report under notice is a statement of the results obtained from an examination of the water supplies and their gathering grounds and storage reservoirs in twenty-three more or less peaty collecting areas in Yorkshire and Lancashire. The object of the examination was to indicate the origin of the plumbo-solvent nature of these waters, and the best methods of preventing or counteracting this action before the water was distributed to consumers. Dr. Houston concurs with Mr. Ackroyd and with other chemists who have studied the subject in these districts in attributing the power of dissolving lead in dangerous quantity to the presence in these waters of acids derived from the peat; and he further intimates his belief that the acid is produced from the peat by the action of certain bacteria found in the peat itself. He finds that the acid nature of the water is frequently not indicated by litmus paper or by other ordinary means, but that it is easily ascertained by the change in colour produced in an alcoholic solution of lacmoid.

The "erosive" action which is exerted on dull lead by dissolved oxygen is considered to be of relatively slight importance, since, in the absence of peaty acids, the amount of solvent action due to this cause is comparatively slight. The peaty acids apparently produce soluble salts of lead and cause the water to bring a much larger proportion of lead into solution than could be introduced by the formation and solution of the oxide alone. Peat is invariably acid in reaction, and peaty water is also always acid. That the solution of the lead by moorland water is due to the peaty acids which it contains has been proved by direct experiment. Further, a decrease of plumbo-solvent power is noticed when these acids are reduced in quantity by various natural causes, or by artificial neutralisation. Indeed, the methods of counteracting plumbo-solvency in peaty water which are adopted in the moorland districts consist in neutralising the acids in the water with carbonate of soda, with carbonate of lime, or with slaked lime. In this connection, it should be remembered that the quantity of slaked lime used must be carefully adjusted, since when it is present unaltered in solution in the water it promotes and does not diminish the plumbo-solvent power.

The variation in degree of solvent action shown by the same moorland supply at different times is shown to be connected with the varying proportions of acid peaty water and of neutralising spring water which the supply contains. In dry weather, the neutral and neutralising water predominates, while rainy weather tends to increase the proportion of superficial acid water which comes out of the peat; these variations in composition markedly influence the plumbo-solvent power of the water.

The author appears to have confined his attention to the

1 Thirtieth Annual Report of the Local Government Board, I900-I9or. Supplement "On Lead Poisoning and Water Supplies." By Dr. Houston. Pp. xi +224 .

NO. I 743, vOL. 67$]$ amounts of lead in solution in the water, and, undoubtedly, these are the common sources of danger. But a not inconsiderable amount of lead may be removed from the metal, and exist at first in solution as hydroxide, and subsequently as a deposit of hydroxycarbonate, when pure soft water acts on lead in the presence of the atmosphere; in water supplies this action is often considerably restricted by the presence of carbonic acid in solution in considerable proportion, or by the presence of silica, sulphate or carbonate in small amount.

The vast amount of detailed information contained in the report is worthy of serious consideration by those who have to deal with the supply of soft peaty water, as is also the recommendation that the seasonal plumbo-solvent power of the different sources from which any particular supply is derived should be accurately known; arrangements can then be made either to avoid the collection of portions of the supply at the times when they possess a dangerous solvent power on lead, or to neutralise them by satisfactory treatment before they are distributed to consumers. F. C.

\section{PROGRESS OF THE NEW VEGETATION OF KRAKATAO.}

$\mathrm{T}^{\mathrm{T}}$ is within a few months of twenty years since the great eruption took place which absoluteiy killed all life in the island of Krakatão. A bout three years later, Dr. Treub visited the island and examined the beginnings of a new vegetation, the results of which were recorded in I888 (NATURE, vol. xxxviii. P 344). He found that the first vegetable settlers on the covering of pumice-stone, lava and ash were microscopic algæ belonging to the Cyanophyceæ. These organisms covered the surface with a slimy layer, which acted as a decomposing agent and created a suitable substratum for ferns, of which about a dozen species were already abundant in 1886 . Dr. Treub also observed a few individuals of fifteen species of flowering plants, most of which had sprung from drift-seeds.

In the spring of 1897 , a party of botanists visited the island, and Dr. O. Penzig has published the results of their investigations and observations (Annales du Jariln Botanique de Buitenzorg, 2me série, iii. (I9O2), pp. 92-II3, with seven views), from which we learn that sixiy-two species of vascular plants were observed on Krakatão and the neighbouring islets, Lang and Verlaten. Fifty of these colonists are flowering plants, representing twenty-one natural orders, and it seems highly probable that they all reached the islands independently of man. Classifying these fifty-three species according to the assumed means by which their seeds were conveyed to the islands, 7.54 per cent. were possibly carried by birds, 32.07 per cent. were probably wind-borne and 60.39 per cent. were almost certainly cast up by the waves of the sea. No additional species of fern appears to have established itself in the islands between 1886 and 1897 . This is inexplicable, because the region is rich in ferns, the spores of which, one would suppose, would be brought by winds in abundance. A part from ferns, the probable "aeolophilous" element consists of eight Compositæ, six grasses and four orchids. After passing the strand belt of vegetation, which is by far the most numerous in species, derse thickets of Phragmites, Saccharum and Gymnothrix were encountered. The interior and higher part of Krakatão is still much less covered with vegetation, ferns largely preponderating. Conspicuous and relatively common amongst the flowering plants was Spathiglottis plicata, a terrestrial orchid. The other orchids are Vanda Szlingi, Arundina speciosa and a species of Phajus. Krakatão is about twenty miles distant from both Java and Sumatra, and the most interesting question suggested by the new vegetation is, How far does it afford a solution of the problem of the origin of the vegetation of much more remote islands which have more than a littoral or coral island fora?

W. BotTing Hemsley.

\section{ANTHROPOLOGICAL NOTES.}

'HE strange cranial deformation known as trigonocephaly, in which the forehead is constricted and more or less pointed, and the temporal region and the base of the skull are broadened, is the subject of a research by Dr. M. Hanotte in l'Anthropologie (tome xiii. No. 5, p. 587).

The weight of the human biain is the subject of a detailed 